\title{
Mentor's Introduction
}

BEVERLY JONES

University of Oregon

Heather Anderson began this study with interests in the larger environment, especially the natural landscape and landscape painters. She wished to use information from her study of these to prepare educational materials. The initial work on this study was done under the direction of June K. McFee. After her retirement, it became my task to assist Heather in narrowing her purpose and designing a research methodology.

Her purpose was narrowed to the design of a strategy for analyzing the lives and works of landscape painters for educational purposes, especially as related to a heightened awareness of the natural landscape. The development of this strategy provided an opportunity for generating a method which, I believe, may be used to analyze the lives and works of artists with other foci in mind, and to determine what content and sequencing seem appropriate for educational purposes relative to those foci. Heather's work represents an initial study using this method. I hope she and others will build on her work by developing educational materials based on the content of this study and by using the methodology developed. 